\title{
Efeito da gramatura sobre a qualidade de colagem lateral da madeira de Tectona grandis
}

\author{
Effect of grammage on the bonding quality of glue side of Tectona grandis wood
}

\section{Ana Paula Namikata Fonte e Rosilani Trianoski}

\author{
Recebido em 14/04/2015 / Aceito em 04/08/2015
}

\section{RESUMO}

A madeira de Tectona grandis Linn f. (teca) é adequada para a confecção de Edge Glued Panels (EGP) devido a sua estabilidade dimensional, propriedades físicas, mecânicas e químicas, além de sua semelhança com madeiras nobres como o mogno. Na geração deste produto, uma variável de elevada importância é a gramatura do adesivo. Neste contexto, este trabalho objetivou avaliar o efeito da gramatura sobre a qualidade de juntas coladas de Tectona grandis. Para a concretização deste trabalho foi utilizada madeira de teca e adesivo Polivinil Acetato. A massa específica e o teor de umidade da madeira foram avaliados de acordo com a norma COPANT 461/1972 e COPANT 460/1972, respectivamente, e as propriedades químicas de acordo com as normas TAPPI. Os sarrafos foram colados utilizando-se quatro gramaturas: $100 \mathrm{~g}$ $\mathrm{m}^{-2}, 140 \mathrm{~g} \mathrm{~m}^{-2}, 180 \mathrm{~g} \mathrm{~m}^{-2}$ e $220 \mathrm{~g} \mathrm{~m}^{-2}$. A qualidade de colagem foi avaliada por meio do ensaio de resistência ao cisalhamento, conforme a norma EN $13354 / 2003$. Os resultados obtidos indicaram que a massa específica aparente média foi de $559 \mathrm{~kg} \mathrm{~m}^{-3}$, o teor de umidade médio de $7,74 \%$ e o teor de extrativos totais de $8,27 \%$. As juntas coladas apresentaram variação na resistência ao cisalhamento de $0,924 \mathrm{MPa}$ a 1,35 MPa para o estado úmido e de 3,01 $\mathrm{MPa}$ a 5,43 MPa para a condição seca. Não houve diferença estatisticamente significativa entre as médias das diferentes gramaturas utilizadas sobre a qualidade da colagem de painéis EGP. Concluiu-se que a madeira de teca apresentou valores adequados de propriedades da madeira, as juntas coladas apresentaram valores qualificados para o padrão brasileiro para o ensaio de cisalhamento e a melhor condição de gramatura encontrada foi de $140 \mathrm{~g} \mathrm{~m}^{-2}$.

PALAVRAS-CHAVE: resistência ao cisalhamento, painel colado lateralmente, painéis, qualidade de colagem, propriedades da madeira.

Universidade Federal do Paraná, Curitiba, PR, Brasil.

*Autor para correspondência <ana.namikata@gmail.com>.

\section{ABSTRACT}

Tectona grandis Linn f. wood (teak) is suitable for making Edge Glued Panels (EGP) due to its dimensional stability, physical, mechanical and chemical properties and its resemblance to hardwoods such as mahogany. In generating those products, a highly important variable is the grammage of the adhesive. In this context, this study aimed to evaluate the effect of grammage on the quality of bonded joints of Tectona grandis. To achieve this work teak wood and adhesive polyvinyl acetate were used. The density and the moisture content of the wood were evaluated according to the standard COPANT 461/1972 and $460 / 1972$, respectively, and the chemical properties in accordance with TAPPI standards. The joints were glued using four grammages: $100 \mathrm{~g} \mathrm{~m}^{-2}, 140 \mathrm{~g} \mathrm{~m}^{-2}$, $180 \mathrm{~g} \mathrm{~m}^{-2}$, and $220 \mathrm{~g} \mathrm{~m}^{-2}$. The quality of bonding was evaluated by means of shear strength and tested according to EN 13354/2003. The results showed that the mean apparent specific mass was $559 \mathrm{~kg} \mathrm{~m}^{-3}$, the average moisture content was $7.74 \%$ and the total content was $8.27 \%$ extractives. The bonded joints showed variation in shear strength of $0.924 \mathrm{MPa}$ to $1.35 \mathrm{MPa}$ for the wet state and $3.01 \mathrm{MPa}$ to 5.43 $\mathrm{MPa}$ for dry conditions. There was no statistically significant difference between the averages of the different weights used on the quality of the EGP panels collage. It was concluded that the teak wood had adequate values of properties of wood, glued together had qualified values for the Brazilian standard for shear testing and the best condition was found with a weight of $140 \mathrm{~g} \mathrm{~m}^{-2}$.

KEYWORDS: shear strength, edge glued panel, panels, quality, wood properties. 


\section{INTRODUÇÃO}

O setor madeireiro no Brasil tem se deparado com dificuldades na obtenção de madeiras de lei devido à exploração seletiva das florestas nativas em áreas cada vez mais abrangentes (CALDEIRA et al. 2000). Os mesmos autores também expressam mais uma dificuldade encontrada nas madeiras provenientes de florestas plantadas, as quais nem sempre apresentam propriedades desejadas para utilizações nobres como a produção de móveis finos e painéis decorativos.

Por outro lado, a teca (Tectona grandis Linn f.) tem sido utilizada para substituir as madeiras nativas por apresentar características estéticas únicas, como a coloração que remete a madeiras de lei como o mogno, boa resistência, trabalhabilidade e estabilidade dimensional (MACEDO et al. 2005). Segundo estes mesmos autores, por tais predicados, esta espécie é considerada uma madeira adequada à confecção de móveis, painéis de madeira colada lateralmente (PCL ou EGP) e outros produtos de maior valor agregado.

O EGP é um painel gerado a partir da colagem lateral de sarrafos, podendo estes, estar ou não, unidos pelo topo com emendas do tipo finger joint (LOPES 2008). Segundo CONTI (2011) este produto oferece uma extensa gama de utilizações, as quais podem se tornar componentes de mobílias e artefatos decorativos. LOPES (2008) complementa que além de componentes de móveis e decoração, podem ser utilizados em portas e janelas de uso interno ou externo, conforme o tipo de adesivo aplicado na formação da união.

Quanto aos aspectos econômicos e mercadológicos deste produto de base florestal, escassas são as informações, e as poucas disponíveis não são recentes. Segundo a ABIMCI (2007), no período entre 1997-2006, este tipo de painel apresentou crescimento anual na produção de $8,5 \%$ e de $108,8 \%$ e consumo crescente de $6,2 \%$ ao ano e $71,8 \%$. Grande parte do EGP é consumida no mercado interno pela indústria moveleira nacional, uma vez que a maioria dos produtores nacionais de EGP opera de forma integrada com as indústrias de móveis; as exportações são direcionadas para Alemanha e Coréia em grande parte (SBS 2008). Dados da ABRAF (2012) indicam que as exportações de painéis colados lateralmente, juntamente com blocks e blanks, molduras e carvão vegetal, somaram U\$163 milhões em 2011. Segundo a ABIMCI (2007), painéis EGP de Pinus spp. eram exportados a US\$ 430 a 450 e de Eucalyptus spp. a
US\$ 510 a 570 por metro cúbico.

Para gerar produtos de elevada qualidade, o setor produtivo de painéis EGP deve se preocupar com alguns fatores que interferem na qualidade de colagem, como a condição da superfície a ser colada, o adesivo utilizado e suas especificações, a gramatura aplicada na colagem, o método de prensagem, o teor de extrativos que podem dificultar a penetração de adesivo na madeira, bem como a procedência e armazenamento da madeira empregada (IWAKIRI 2005). Segundo CONTI (2011) os adesivos à base de acetato de polivinila (PVA) e a emulsão polimérica de isocianato (EPI) são os mais adequados para a confecção de painéis EGP e mobiliário, pelo fato de apresentar baixo custo e alta produtividade no caso do PVA, e elevada resistência da linha de cola no caso do EPI.

Uma das variáveis importantes para a produção dos painéis EGP é a gramatura, a qual pode alterar a resistência mecânica de um painel, tanto quando é utilizado adesivo em quantidade menor que o ideal, bem como se for utilizada uma quantidade excedente ao recomendado, sustenta IWAKIRI et al (2013). Segundo a perspectiva desse mesmo autor, é importante ter precisão na dosagem da gramatura para obter uma colagem com a qualidade adequada, a qual pode ser estabelecida em função da espécie de madeira e do produto final.

Em relação às propriedades físicas da madeira, MARRA (1992) constata que as propriedades físicas mais importantes no que diz respeito à colagem de madeiras são a massa específica e o teor de umidade, as quais afetam de formas distintas a mobilidade do adesivo e tensões na linha de cola.

IWAKIRI (2005) corrobora que a massa específica representa uma relação inversa com a porosidade e a capacidade de penetração do adesivo em sua estrutura lenhosa. MARRA (1992) esclarece que o aumento da massa específica tende a aumentar a resistência da linha de cola, por exemplo, em madeiras de baixa massa específica, as quais possuem maior porosidade, absorvem quantidade excessiva de adesivo, ou seja, ocorre maior penetração de adesivo, podendo ocasionar uma linha de cola "faminta".

Em relação ao teor de umidade, MARRA (1992) explica que as mudanças do teor causam alterações dimensionais as quais induzem tensões na linha de cola, sendo este efeito mais pronunciado em madeiras de alta massa específica. Com relação a esse assunto, SELBO (1975) afirma que a madeira 
com teor de umidade muito abaixo do indicado, retira água da linha de cola muito rapidamente, iniciando o processo de cura do adesivo antes do tempo esperado, tornando-o incapaz de preencher e umectar sob pressão na prensa. Esse autor ainda previne que em caso de umidade elevada na madeira, a cura e a secagem da linha de cola serão deficientes, aumentando o tempo de prensagem e diminuindo a resistência na linha de cola, podendo ocasionar bolhas de vapor durante a prensagem.

Em relação às propriedades químicas da madeira que podem influenciar a qualidade dos painéis, pode-se dizer que a quantidade e o tipo de extrativos encontrados na madeira também podem gerar interferências nas reações de polimerização do adesivo influenciando a qualidade do produto final, no caso o painel de EGP (LIMA et al. 2008). Em geral, o teor de extrativos tende a ser inferior a 10\% (SJÖSTRÖM 1981), no entanto, madeiras tropicais ou de massa específica elevada podem apresentar quantidades maiores dificultando o processo de colagem, na qual, segundo MOSLEMI (1974), o elevado teor desses componentes pode reduzir consideravelmente a resistência à adesão interna, caracterizando uma linha de cola de baixo desempenho.

$\mathrm{O} \mathrm{pH}$ da madeira pode ser alterado de acordo com a migração de extrativos de camadas mais internas para camadas superficiais alterando as condições de colagem (IWAKIRI, 2005). Essa alteração, segundo o mesmo autor, pode proporcionar o pré-endurecimento do adesivo impedindo a habilidade de fluidez, umectação e penetração.

Tendo em vista os inúmeros fatores que afetam a qualidade de colagem, bem como a importância de se gerar produtos com o menor custo possível ou a maximização da matéria prima, este trabalho objetivou analisar o efeito de diferentes gramaturas sobre a qualidade de juntas coladas de $T$. grandis.

\section{MATERIAL E MÉTODOS}

A madeira de $T$. grandis utilizada neste trabalho é proveniente de lotes comerciais oriundos de florestas plantadas, obtidos pela empresa Henkel Ltda. e cedidas pela à Universidade Federal do Paraná. O material apresentava-se na forma de sarrafos, os quais possuíam grande variabilidade, constituindo-se de peças localizadas próximo ao cerne (medula) e peças obtidas próximo a periferia do tronco. Os sarrafos foram climatizados até peso constante em câmara climática com condições ambientais de $20 \pm 2{ }^{\circ} \mathrm{C}$ de temperatura e $65 \pm 5 \%$ de umidade relativa de acordo com a norma COPANT 459/1972 e em seguida processados mecanicamente, obtendo-se peças com dimensões de 26x5x2 cm, respectivamente, para comprimento, largura e espessura. Durante a padronização das peças realizou-se amostragem de material para determinação das propriedades químicas e do teor de umidade.

As propriedades químicas da madeira foram determinadas de acordo com as normas TAPPI e NBR conforme a Tabela 1.

Para a determinação do $\mathrm{pH}$ da madeira foi efetuada adaptação da Norma TAPPI 252/2002. Foram pesados $2 \mathrm{~g}$ de serragem absolutamente seca, as quais foram transferidas para erlenmeyer, sendo posteriormente adicionados $100 \mathrm{ml}$ de água destilada. O material foi conservado sob fervura em banho maria durante uma hora e após o resfriamento a temperatura ambiente $\left(23{ }^{\circ} \mathrm{C}-24{ }^{\circ} \mathrm{C}\right)$ foram executadas as medições. As leituras foram efetuadas em pHmetro digital após o intervalo de duas e 24 horas.

O teor de umidade da madeira foi obtido de acordo a metodologia preconizada pela norma COPANT 460/1972. Já a massa específica aparente foi determinada a partir dos sarrafos preparados para a colagem e seguiu as recomendações da mesma norma.

Após a preparação dos sarrafos, foi realizada a seleção destes, assim como a identificação da melhor face de colagem. Os sarrafos foram colados com Adesivo Polivinil Acetato (PVAc), que é o adesivo mais utilizado pela indústria devido a sua grande disponibilidade e preço acessível. Foi cedido pela empresa Henkel Ltda., o qual teve suas propriedades físico-químicas avaliadas conforme as normas sobre: o teor de sólidos de $47 \%$, viscosidade de $6034 \mathrm{cP}, \mathrm{pH}$ de 4,2 e densidade de $1070 \mathrm{~kg} \mathrm{~m}^{-3}$ (Tabela 1).

Os sarrafos foram colados com quatro diferentes gramaturas de adesivo, constituindo quatro tratamentos, sendo: $100 \mathrm{~g} \mathrm{~m}^{-2}, 140 \mathrm{~g} \mathrm{~m}^{-2}, 180 \mathrm{~g} \mathrm{~m}^{-2}$ e $220 \mathrm{~g} \mathrm{~m}^{-2}$ e quatro repetições por tratamento. A partir de cada repetição foram obtidos 10 corpos de prova, totalizando 40 amostras por tratamento. $\mathrm{O}$ adesivo foi aplicado nos sarrafos com o auxílio de um rolo de espuma para maior homogeneidade, sua distribuição foi observada visualmente e a gramatura foi controlada por meio de uma balança digital.

Os parâmetros de prensagem foram préestabelecidos de acordo com as especificações 
Tabela 1 - Relação de normas utilizadas para determinar as propriedades químicas, físicas, do adesivo e ensaios de cisalhamento na linha de cola.

Table 1 - List of standards used to determine the chemical, physical, adhesive properties and shear tests in the glue line.

\begin{tabular}{lc}
\hline \multicolumn{1}{c}{ Norma } & Ensaio \\
\hline TAPPI 207/1994 & Teor de extrativos em água fria e quente \\
TAPPI 211/1994 & Teor de cinzas \\
TAPPI 212/1994 & Teor de extrativos em NaOH 1\% \\
NBR 14853/2002 & Teor de extrativos em etanol-tolueno e extrativos totais \\
NBR 7989/2003 & Teor de lignina insolúvel \\
EN 542/2003 & Densidade \\
EN 827/2006 & Teor de sólidos \\
EN 12145/2001 & Viscosidade \\
EN 19092/2000 & pH \\
EN 323/2002 & Determinação da massa específica aparente \\
EN 322/2003 & Determinação do teor de umidade \\
EN 13354/2003 & Ensaio de cisalhamento na linha de cola e avaliação por meio do \\
NBR ISO 12466-2/2006 & $5^{\circ}$ percentil \\
& Porcentagem de falha da madeira
\end{tabular}

utilizadas pela indústria. Foi utilizado o sistema de prensagem a alta frequência conforme a Figura 1, cuja temperatura foi de $90^{\circ} \mathrm{C}$, pressão de $0,8 \mathrm{MPa}$ e tempo de 2,5 minutos, sendo este procedimento realizado no Laboratório de Aplicações para a Madeira da Henkel Ltda., Curitiba - PR.

Após a prensagem, os painéis foram climatizados por sete dias para cura total do adesivo e posteriormente seguiram para a confecção dos corpos de prova. A massa específica aparente dos painéis e o teor de umidade foram determinados de acordo com as normas da Tabela 1, bem como os ensaios de para avaliação do desempenho da qualidade de colagem dos painéis. A norma referente ao ensaio de cisalhamento na linha de cola contempla os valores obtidos no $5^{\circ}$ percentil inferior em estado úmido.

Os resultados dos ensaios foram submetidos à análise estatística por meio do Teste de Grubb's para avaliar a ocorrência de outliers, Teste de Bartlett para verificar a homogeneidade de variância e Análise de variância. Quando a Anova indicou a ocorrência de diferença estatística significativa em alguma das propriedades avaliadas procedeu-se o teste de comparação de médias de Tukey. Todos os testes foram efetuados a partir do pacote estatístico Statgraphics Centurion XVI, a 95\% de probabilidade, sendo o nível de significância de 5\%.

\section{RESULTADOS E DISCUSSÃO}

A madeira de $T$. grandis empregada nesta pesquisa apresentou massa específica aparente de $559 \mathrm{~kg} \mathrm{~m}^{-3}$ (Tabela 2), a qual a classifica como uma madeira de média massa específica segundo MELO et al. (1990), que relatam que esta classe apresenta intervalo de $510 \mathrm{~kg} \mathrm{~m}^{-3}$ a $720 \mathrm{~kg} \mathrm{~m}^{-3}$.

Este resultado pode indicar que esta propriedade não afetará acentuadamente as ligações adesivas, o qual pode ser corroborado segundo as afirmações de IWAKIRI (2005), o qual relata que em madeiras de baixa massa específica ocorre maior penetração de adesivo, podendo ocasionar uma linha de cola "faminta".

Por outro lado, BURGER \& RICHTER (1991) 


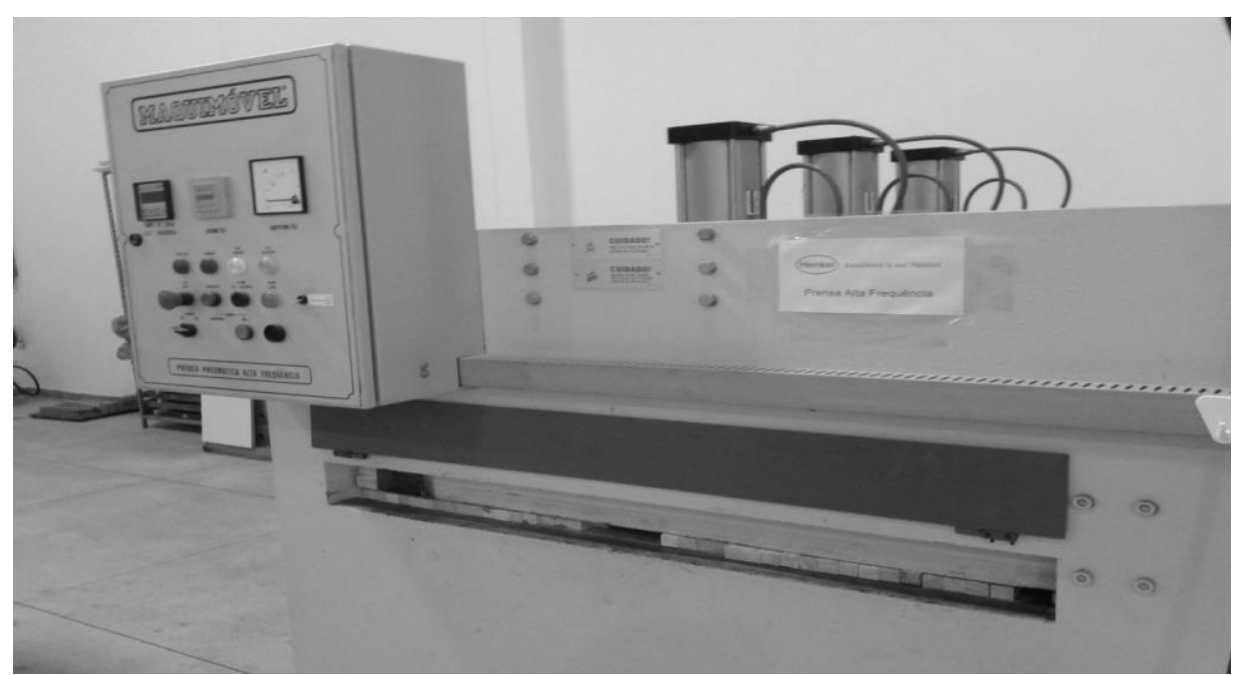

Figura 1 - Prensa Maquimóvel usada no processo de prensagem com sarrafos de Tectona grandis com pressão superior.

Figure 1 - Maquimóvel press machine used for pressing process with battens of Tectona grandis with higher pressure.

Tabela 2 - Resultados médios das propriedades físico-químicas da madeira de Tectona grandis.

Table 2 - Average results of physicochemical wood properties of Tectona grandis.

\begin{tabular}{lcc}
\hline \multicolumn{1}{c}{ Propriedades } & Valor médio & CV (\%) \\
\hline Massa específica $\left(\mathrm{g} \mathrm{cm}^{-3}\right)$ & 0,559 & 6,39 \\
Teor de umidade $(\%)$ & 7,74 & 10,50 \\
Teor de extrativos em água fria (\%) & 3,61 & 2,75 \\
Teor de extrativos em água quente (\%) & 4,97 & 3,07 \\
Teor de extrativos em NaOH (\%) & 15,42 & 0,71 \\
Teor de cinzas (\%) & 0,49 & 0,28 \\
Teor de extrativos em etanol tolueno (\%) & 5,25 & 3,83 \\
Teor de extrativos totais (\%) & 8,27 & 0,90 \\
pH & 4,74 & 2,30 \\
Teor de lignina (\%) & 33,97 & 3,71 \\
\hline
\end{tabular}

esclarecem que madeiras com alta massa específica apresentam menor volume de espaços vazios para penetração do adesivo, acarretando redução da resistência da ligação adesiva entre as peças coladas. SELLERS (1985) complementa a dificuldade de colagem de madeiras de alta massa específica, relatando que madeiras com esta característica requerem adesivos de melhor qualidade e maior controle dos procedimentos de colagem.

Outro fator inerente à propriedade de massa específica e que reflete no comportamento da madeira frente às diversas utilizações é sua variabilidade, em que baixos coeficientes de variação sempre são desejados. De acordo com o FPL (1974), a variação de até $10 \%$ para a massa específica pode ser assumida, o que indica a partir do valor obtido que o material utilizado se apresenta relativamente homogêneo e que não será uma variável com acentuada influência entre as colagens dos diferentes tratamentos.

Ainda em referência à massa específica, os valores médios encontrados são similares aos mencionados por LAMPRECHT (1990) que descreve 
um valor médio de $650 \mathrm{~kg} \mathrm{~m}^{-3}$; aos de TSOUMIS (1991) que relata valores de $670 \mathrm{~kg} \mathrm{~m}^{-3}$ para massa específica aparente entre $12 \%$ e $15 \%$ de umidade; aos de CASTRO \& RAIGOSA (2000), cujo valor médio foi de $580 \mathrm{~kg} / \mathrm{m}^{3}$ para massa específica básica de árvores com 17 anos cultivadas na Costa Rica, aos obtidos por MOTTA (2011) com valor médio de 620 $\mathrm{kg} / \mathrm{m}^{3}$ para massa específica aparente a $15 \%$ a partir de árvores com 15 anos de idade cultivada no estado de Minas Gerais, e que as diferenças encontradas entre os diferentes estudos, possivelmente estão associadas à procedência, idade, solo, condições climáticas, entre outros fatores.

Em relação ao teor de umidade da madeira, verifica-se que o valor médio encontrado para a umidade de equilíbrio foi de 7,74\% (Tabela 2), sendo este inferior ao intervalo de variação recomendado pelo fabricante para a utilização do adesivo PVA, que é de $8 \%$ a $12 \%$. Tal resultado pode ser influência de uma secagem com temperatura mais elevada, a qual tem implicações sobre a umectação e contaminação de superfície em processos de colagem e que, segundo MARRA (1992), interferem nas funções de mobilidade do adesivo como fluidez, transferência, penetração, umectação e solidificação.

Os valores médios encontrados para as propriedades químicas demonstraram que a madeira utilizada neste estudo apresentou-se de acordo com o intervalo descrito por FENGEL \& WEGENER (1989) que relatam para a T. grandis proveniente da Ásia valores de extrativos totais que variam de 1 a $13 \%$, teor de lignina varia de 29,3 a $39,1 \%$ e valores de extrativos em água quente entre 1,8 e 6,2\%, assim como, aos mencionados por TSOUMIS (1991) que descreve que para as espécies folhosas os valores de extrativos em água fria variam de 0,2 a $8,9 \%$, os extrativos em água quente variam de 0,3 a $11 \%$, e que o teor de lignina encontra-se entre 14 e $36,4 \%$.

Comparando-secomoteor de extrativos de Pinus spp., tendo em vista ser a espécie tradicionalmente utilizada para a produção de painéis EGP, e cujo teor normalmente varia de 2,5 a $4,5 \%$ segundo KLEPPE (1970), nota-se que $T$. grandis, apresenta valor superior às espécies deste gênero, o que pode gerar influência negativa sobre a polimerização do adesivo, e que pode ser corroborada por MOSLEMI (1974), que relata o elevado teor de extrativos pode reduzir a resistência à adesão interna. Por outro lado, vale ressaltar também, e de acordo com LIMA et al. (2007), que as reações de polimerização do adesivo e as reações entre adesivos e extrativos dependem não somente da quantidade, mas também da natureza do extrativo.

$\mathrm{O}$ valor de $\mathrm{pH}$ obtido para a madeira de $T$. grandis, de 4,74 (Tabela 2), apresenta-se dentro do intervalo relatado por STAMM (1964), o qual informa que o $\mathrm{pH}$ da madeira varia entre 3,5 a 5,5. De acordo com KOLLMANN et al. (1975) e IWAKIRI (2005), espécies com $\mathrm{pH}$ muito baixo podem dificultar o processo de colagem de produtos de madeiras, o que aparentemente não deverá ser observado neste trabalho devido ao valor apresentado pela espécie.

Os valores médios da massa específica aparente não apresentaram diferença estatística significativa entre os diferentes tratamentos (Tabela 2), ou seja, a seleção e distribuição dos sarrafos em cada tratamento foram adequadas, eliminando a influência da massa específica sobre a penetração do adesivo e consequentemente sobre a resistência.

Em relação ao teor de umidade, verifica-se a ocorrência de diferença estatística apenas entre os tratamentos 1 e 4 , respectivamente, colados com 100 e $220 \mathrm{~g} \mathrm{~m}^{-2}$. Este resultado, possivelmente, está relacionado com o aumento da quantidade de adesivo aplicada, onde maior quantidade de adesivo implica em maior umedecimento da superfície da madeira, alterando ligeiramente, o teor de umidade final do produto.

Os resultados médios de resistência ao cisalhamento (Tabela 3) apresentaram-se relativamente baixos, cujo resultado pode ser atribuído ao adesivo utilizado, em que o PVA é tradicionalmente reconhecido como um adesivo de baixa resistência à umidade. Outro fator que pode ter exercido influência sobre a qualidade de colagem, diz respeito à baixa umidade de equilíbrio da madeira antes desta, cujo teor de umidade médio dos sarrafos foi de $7,74 \%$, inferior ao recomendado pelo fabricante do adesivo, que é de 8 a $12 \%$. Neste caso, pode haver a retirada da água mais rapidamente da linha de cola, impedindo que o adesivo seja capaz de preencher e umectar adequadamente os espaços porosos dos elementos celulares da madeira durante a prensagem a alta frequência.

Verifica-se ainda, que não houve diferença estatística significativa entre os valores médios dos tratamentos propostos, entretanto, pode ser observado um ligeiro aumento da resistência com o aumento da gramatura até a gramatura de $180 \mathrm{~g} / \mathrm{m}^{2}$, e redução com a aplicação da gramatura de $220 \mathrm{~g} \mathrm{~m}^{-2}$. Estes resultados 
Tabela 3 - Resultados médios da resistência ao cisalhamento no estado úmido de Tectona grandis.

Table 3 - Average results of shear strength - wet condition for Tectona grandis.

\begin{tabular}{|c|c|c|c|c|c|}
\hline Tratamento & $\begin{array}{c}\text { Massa } \\
\text { específica } \\
\left(\mathrm{g} \mathrm{cm}^{-3}\right)\end{array}$ & $\begin{array}{c}\text { Teor de } \\
\text { Umidade } \\
(\%)\end{array}$ & $\begin{array}{c}\text { Resistência ao } \\
\text { Cisalhamento } \\
\text { (MPa) }\end{array}$ & $\begin{array}{c}5^{\circ} \text { Percentil } \\
\text { Inferior } \\
(\mathrm{MPa})\end{array}$ & $\begin{array}{l}\text { Falha } \\
(\%)\end{array}$ \\
\hline $1-100 \mathrm{~g} \mathrm{~m}^{-2}$ & $\begin{array}{c}0,570 \mathrm{a} \\
(3,56)\end{array}$ & $\begin{array}{l}7,89 \mathrm{~b} \\
(4,80)\end{array}$ & $\begin{array}{r}0,92 \mathrm{a} \\
(89,52)\end{array}$ & 0,23 & 0 \\
\hline $2-140 \mathrm{~g} \mathrm{~m}^{-2}$ & $\begin{array}{c}0,563 \mathrm{a} \\
(8,36)\end{array}$ & $\begin{array}{c}7,97 \mathrm{ab} \\
(4,40)\end{array}$ & $\begin{array}{r}0,96 \mathrm{a} \\
(91,99)\end{array}$ & 0,24 & 0 \\
\hline $3-180 \mathrm{~g} \mathrm{~m}^{-2}$ & $\begin{array}{c}0,559 \mathrm{a} \\
(4,90)\end{array}$ & $\begin{array}{c}7,92 \mathrm{ab} \\
(7,35)\end{array}$ & $\begin{array}{l}1,35 \mathrm{a} \\
(70,02)\end{array}$ & 0,58 & 0 \\
\hline $4-220 \mathrm{~g} \mathrm{~m}^{-2}$ & $\begin{array}{c}0,570 \text { a } \\
(3,85)\end{array}$ & $\begin{array}{l}8,47 \mathrm{a} \\
(6,78)\end{array}$ & $\begin{array}{c}0,94 \mathrm{a} \\
(95,68)\end{array}$ & 0,27 & 2 \\
\hline $\mathrm{F}$ & 0,34 & 4,07 & 0,29 & & \\
\hline$P$ & $0,7965^{\mathrm{ns}}$ & $0,0134 *$ & $0,8333^{\text {ns }}$ & & \\
\hline
\end{tabular}

Médias seguidas de mesma letra na mesma coluna são estatisticamente iguais pelo teste de Tukey a 95\% de probabilidade. Valores entre parênteses referem-se ao coeficiente de variação das amostras.

indicam que a aplicação de uma maior quantidade de adesivo, implica em aumento do custo, sem apresentar benefícios na qualidade de colagem, pois essa quantidade é excessiva e resulta em escorrimento de adesivo para fora da área de colagem. Vale ressaltar ainda, que durante a colagem foram observados escorrimentos nas laterais das juntas, indicando que nem todo o volume que foi aplicado no tratamento 4 $\left(220 \mathrm{~g} \mathrm{~m}^{-2}\right)$ participou da ligação adesiva.

Em relação ao $5^{\circ}$ percentil inferior, observase também, resultados médios muito baixos, os quais apresentaram-se inferiores ao requisito mínimo da norma EN 13354:2003 em 2,5 MPa, assim como valores médios de falha, iguais ou próximos à $0 \%$ (Tabela 4), demonstrando a baixa resistência do adesivo a base de PVA. Segundo CORRÊA (1997), a cura do adesivo PVA ocorre pela simples evaporação do solvente (água), resultando numa colagem de baixa resistência quando expostas às condições de alta umidade.

Em relação aos resultados das propriedades físicas e mecânicas das juntas coladas em estado seco, observa-se que os valores médios da massa específica aparente não apresentaram diferença estatística significativa entre os diferentes tratamentos (Tabela 4), comportamento já observado nas juntas avaliadas em estado úmido. Já em relação ao teor de umidade, as amostras nesta condição de ensaio apresentaram teor de umidade médio estatisticamente igual entre os tratamentos, podendo-se neste caso, eliminar a influência do teor de umidade sobre os resultados de qualidade de colagem.

Em relação ao ensaio de resistência ao cisalhamento no estado seco, realizado para obter-se um valor de referência para utilizações em condições secas, nota-se também que não houve diferença estatística significativa entre os valores médios dos diferentes tratamentos propostos, sendo observado também, como nas juntas avaliadas em estado úmido, um aumento da resistência com o acréscimo da gramatura até a utilização de $180 \mathrm{~g} \mathrm{~m}^{-2}$. Estes resultados corroboram a consideração anterior que a aplicação de uma maior quantidade de adesivo não gerou benefícios em termos de resistência à colagem, neste estudo.

Considerando o requisito mínimo da norma EN 13354:2003, utilizado para validar produtos em condições úmidas, mas tomando-se também como referencial para a condição seca, nota-se que somente o tratamento com gramatura de $140 \mathrm{~g} / \mathrm{m}^{2}$ atendeu ao valor mínimo de $2,5 \mathrm{MPa}$ para o $5^{\circ}$ percentil inferior, indicando que nesta condição, a gramatura de 
Tabela 4 - Resultados médios da resistência ao cisalhamento - estado seco de Tectona grandis.

Table 4 - Average values of shear strength - dry state for Tectona grandis.

\begin{tabular}{cccccc}
\hline Tratamento & $\begin{array}{c}\text { Massa } \\
\text { específica } \\
\left(\mathrm{g} \mathrm{cm}^{-3}\right)\end{array}$ & $\begin{array}{c}\text { Teor de } \\
\text { Umidade } \\
(\%)\end{array}$ & $\begin{array}{c}\text { Resistência ao } \\
\text { Cisalhamento } \\
(\mathrm{MPa})\end{array}$ & $\begin{array}{c}5^{\circ} \text { Percentil } \\
\text { Inferior } \\
(\mathrm{MPa})\end{array}$ & $\begin{array}{c}\text { Falha } \\
(\%)\end{array}$ \\
\hline $1-100 \mathrm{~g} \mathrm{~m}^{-2}$ & $0,570 \mathrm{a}$ & $7,89 \mathrm{~b}$ & $0,92 \mathrm{a}$ & 0,23 & 0 \\
& $(3,56)$ & $(4,80)$ & $(89,52)$ & 0,24 & 0 \\
$2-140 \mathrm{~g} \mathrm{~m}^{-2}$ & $0,563 \mathrm{a}$ & $7,97 \mathrm{ab}$ & $0,96 \mathrm{a}$ & & 0 \\
$3-180 \mathrm{~g} \mathrm{~m}^{-2}$ & $0,559 \mathrm{a}$ & $7,92 \mathrm{ab}$ & $1,35 \mathrm{a}$ & 0,58 & 2 \\
& $(4,90)$ & $(7,35)$ & $(70,02)$ & 0,27 & \\
$4-220 \mathrm{~g} \mathrm{~m}^{-2}$ & $0,570 \mathrm{a}$ & $8,47 \mathrm{a}$ & $0,94 \mathrm{a}$ & & \\
\hline $\mathrm{F}$ & $(3,85)$ & $(6,78)$ & $(95,68)$ & & \\
$P$ & 0,34 & 4,07 & 0,29 & & \\
\hline
\end{tabular}

Médias seguidas de mesma letra na mesma coluna são estatisticamente iguais pelo teste de Tukey a 95\% de probabilidade. Valores entre parênteses referem-se ao coeficiente de variação das amostras.

$140 \mathrm{~g} \mathrm{~m}^{-2}$ é suficiente para a colagem, maximizando a matéria prima.

Outro fator a ser considerado nos estudos referentes a qualidade de juntas coladas, diz respeito à norma utilizada para desenvolvimento dos métodos de ensaio e critérios de aceitação. Sabe-se que a norma EN 13354:2003, tem sido a mais utilizada para esta finalidade, no entanto, segundo PRATA (2010), esta norma ou é excessivamente exigente ou a qualidade de colagem das espécies de rápido crescimento do Brasil não é compatível com a referida norma. Desta forma, os valores obtidos no presente trabalho serão, a partir deste momento, comparados com outras pesquisas.

Considerando o estudo conduzido por PRATA (2010), verifica-se que este autor ao avaliar espécies de Pinus spp., obteve para o Pinus taeda L. que é a espécie mais utilizada para a produção de painéis de colagem lateral, assim como para as demais espécies de pinus tropicais valores médios de resistência ao cisalhamento úmido de 2,28 a 2,88 $\mathrm{MPa}$ e valores para o $5^{\circ}$ percentil inferior entre 1,38 a $2,18 \mathrm{MPa}$, em que estes valores também não atendem o requisito mínimo de 2,50 $\mathrm{MPa}$, porém são superiores aos encontrados nesta pesquisa.

ALMEIDA(2013) utilizando madeiras tropicais para produção de painéis colados lateralmente com adesivo PVA, obteve valores de resistência ao cisalhamento em estado seco de 0,50 a 4,26 $\mathrm{MPa}$ e de 0,28 a $0,90 \mathrm{MPa}$, quando o ensaio foi realizado após o pré-tratamento de imersão em água. Com base neste estudo, pode-se verificar que com exceção da espécie Pterogyne nitens Tul. colada com gramatura de $200 \mathrm{~g} \mathrm{~m}^{-2}$, as demais espécies apresentaram valores inferiores aos obtidos na pesquisa, quando avaliados a seco, e similares quando avaliados à úmido.

Em relação ao efeito da gramatura sobre a resistência ao cisalhamento, verifica-se que PRATA (2010) ao utilizar as gramaturas de 160 e $200 \mathrm{~g}$ $\mathrm{m}^{-2}$, obteve incremento médio geral nas espécies de 2,56 MPa para 2,67 MPa, sendo estes valores estatisticamente iguais.

Ainda em relação ao estudo de PRATA (2010), ao se avaliar as seis espécies separadamente, apenas o $P$. taeda, apresentou aumento significativo de resistência, sendo este resultado justificado pelo referido autor, como efeito do menor teor de extrativos na espécie, os quais não afetaram a penetração do adesivo. ALMEIDA (2013) também estudou o efeito do aumento da gramatura do adesivo PVA nas espécies tropicais e observou que o aumento da gramatura de 150 para $200 \mathrm{~g} \mathrm{~m}^{-2}$ proporcionou um ligeiro aumento na resistência na condição seca, 
porém, não foram observadas diferenças estatísticas significativas. Já no ensaio úmido, a mesma autora observou que o aumento da gramatura gerou aumento de resistência apenas em algumas espécies, não sendo também, constatada diferença estatística significativa em nenhuma delas.

BILA (2014) também avaliou a influência da gramatura em espécies amazônicas e não obteve diferença estatística significativa entre as gramaturas de 120 e $200 \mathrm{~g} \mathrm{~m}^{-2}$, apenas um ligeiro aumento de 4,62 para 4,90 MPa. Os valores encontrados nas pesquisas citadas são bastante similares ao deste trabalho, que indica não haver grandes efeitos da gramatura sobre a resistência, podendo-se com isso, maximizar a dosagem do adesivo e diminuir o custo do produto final, além de que não haverá desperdício de adesivo.

\section{CONCLUSÕES}

A massa específica obtida pelo estudo foi de $559 \mathrm{~kg} \mathrm{~m}^{-3}$ e está coerente com valores citados em literatura para $T$. grandis e é considerado um valor adequado para a produção de painéis EGP.

O teor de umidade apresentou valor de 7,74\%, considerado inferior ao recomendado pelo fabricante para a colagem de madeira.

Os resultados encontrados para o de teor de extrativos totais $(8,27 \%)$, lignina $(33,97)$ e cinzas $(0,49 \%)$ são semelhantes aos valores encontrados em estudos com a espécie de $T$. grandis, porém não apresentaram influência na qualidade da colagem.

Não houve diferença significativa entre as diferentes gramaturas avaliadas em termos de resistência da colagem lateral.

Recomenda-se a utilização de gramaturas de 140 a $180 \mathrm{~g} \mathrm{~m}^{-2}$ na produção de EGP de T. grandis.

\section{REFERÊNCIAS}

ALMEIDA VC. 2013. Avaliação do potencial de uso de resíduos de madeira tropical para produção de painéis colados lateralmente - EGP. Tese (Doutorado em Ciências Agrárias) Curitiba: UFPR. 123 p.

ABIMCI-ASSOCIAÇÃOBRASILEIRADAINDÚSTRIA DA MADEIRA PROCESSADA MECANICAMENTE. 2007. Estudo setorial. Curitiba: ABIMCI. $40 \mathrm{f}$.

ABRAF - ASSOCIAÇÃO BRASILEIRA DE PRODUTORES DE FLORESTAS PLANTADAS. 2012. Anuário estatístico da ABRAF 2012, ano base 2011. Brasília: ABRAF. $150 \mathrm{f}$.

BILA NF. 2014. Avaliação da qualidade de juntas coladas de seis espécies de madeira tropicais da Amazônia. Dissertação (Mestrado em Ciências Florestais). Curitiba: UFPR. 76 p.

BURGER LM \& RICHTER HG. 1991. Anatomia da Madeira. São Paulo: Nobel. 154 p.

CALDEIRA SF et al. 2000. Caracterização e avaliação da qualidade dos frutos de teca (Tectona grandis 1.f.) produzidos no Mato Grosso. Rev. Bras. Sem. 22: 216-224. CASTRO FY \& RAIGOSA J. 2000. Crecimiento y Propiedades Físico - Mecánicas de La madera de teca (Tectona grandis) de 17 años de edad en San Joaquín de Abangares, Costa Rica. Agron. Costarricense 24: 7-23.

CONTI AC. 2011. Resistência mecânica de juntas coladas em madeira de Eucalyptus sp. Tese (Doutorado na Área de Materiais). Guaratinguetá: UNESP. 103 p.

COPANT-COMISIÓN PANAMERICANADENORMAS TÉCNICAS. 1972. COPANT 459. Acondicionamento de las maderas destinadas a los ensayos físicos y mecánicos. COPANT - COMISIÓN PANAMERICANA DE NORMAS TÉCNICAS. 1972. COPANT 460. Método de determinación de la humidad.

COPANT - COMISIÓN PANAMERICANADENORMAS TÉCNICAS. 1972. COPANT 461. Determinación del peso específico aparente.

CORRÊA C. 1997. Técnicas de colagem de madeira com adesivos vinílicos. Borden: Química Indústria e comércio Ltda. 68 p. (Boletim Técnico).

EN - EUROPEAN STANDARD. 2000. EN 19.092: Adhesives - Determination of viscosity.

EN - EUROPEAN STANDARD. 2001. EN 12.145: Adhesives - Adhesives of $\mathrm{pH}$ - Test Method.

EN - EUROPEAN STANDARD. 2002. EN 323: Painéis derivados de madeira - Determinação da massa volúmica (versão portuguesa).

EN - EUROPEAN STANDARD. 2003. EN 322: Painéis derivados de madeira - Determinação do teor de umidade (versão portuguesa).

EN - EUROPEAN STANDARD. 2003. EN 542: Adhesives - Determination of density.

EN - EUROPEAN STANDARD. 2003. EN 13354. Solid wood panel - bonding quality - test method. Technical specification.

EN - EUROPEAN STANDARD. 2006. EN 827: Adhesives - Determination of conventional solids content and mass solids.

FENGEL D \& WEGENER G. 1989. Wood. Chemistry: Ultrastructure: Reactions. Berlin:Walter de Gruyter.

FPL-FOREST PRODUCTS LABORATORY. 1974. Wood handbook: wood as engineering material. Washington: U.S. Department of Agriculture. $521 \mathrm{p}$.

IWAKIRI S. 2005. Painéis de Madeira Reconstituída. Curitiba: FUPEF. 247 p.

IWAKIRI $S$ et al. 2013. Avaliação da resistência de juntas coladas da madeira de Eucalyptus benthamii com diferentes adesivos e faces de colagem. Sci. Forest. 41: 411-416. 
KLEPPE PJ. 1970. The process of, and products from, kraft pulping of southern pine. Forest Prod. J. 20: 50-59.

KOLLMANN FFP et al. 1975. Principles of wood science and technology. Wood based materials. V2. Berlin: Springer-Verlag. p. 154-283.

LAMPRECHT H. 1990. Silvicultura en los trópicos: los ecosistemas forestales en los bosques tropicales y sus especies arbóreas; posibilidades y métodos para un aprovechamiento sostenido. Deutsche Gesellschaft fur Technische Zusammenarbeit (GTZ) GmbH. 335 p.

LIMA CKP et al. 2007. Características anatômicas e química da madeira de clones de Eucalyptus e sua influência na colagem. Cerne 13: 123-129.

LIMA CKP et al. 2008. Colagem da madeira de clones de Eucalyptus sp. com três adesivos comerciais. Sci. Forest. 36: 73-77.

LOPES MC. 2008. Espectroscopia no infravermelho próximo aplicada na avaliação de painéis de madeira colados lateralmente. Tese (Doutorado em Engenharia Florestal) Curitiba: UFPR. 130 p.

MACEDO RLG et al. 2005. Desenvolvimento inicial de Tectona grandis 1.f. (teca) em diferentes espaçamentos no município de Paracatu, MG. Cerne 11: 61-69.

MARRA AA. 1992. Technology of Wood Bonding. New York: Van Nostrand Reinhold. $453 \mathrm{p}$.

MELO JE et al. 1990. Classes de densidade para madeiras da Amazônia Brasileira. In: $6^{\circ}$ Congresso Florestal Brasileiro, Florestas e Meio Ambiente: Conservação e Produção, Patrimônio Social. Anais... Campos do Jordão. p. 695-699.

MOSLEMI AA. 1974. Particleboard vol. 1: Materials. Southern Illinois University Press. London. 244 p.

MOTTA JP. 2011. Propriedades tecnológicas da madeira de Tectona grandis 1.f. proveniente do Vale do Rio Doce, Minas Gerais. Dissertação (Mestrado em Ciências Florestais). Jerônimo Monteiro: UFES. 112 p.

ABNT - ASSOCIAÇÃO BRASILEIRA DE NORMAS TÉCNICAS. 2002. NBR 14853: madeira - determinação do material solúvel em etanol-tolueno e em diclorometano. Rio de Janeiro: ABNT.

ABNT - ASSOCIAÇÃO BRASILEIRA DE NORMAS TÉCNICAS. 2003. NBR 7989. Determinação da lignina insolúvel em ácido.

ABNT - ASSOCIAÇÃO BRASILEIRA DE NORMAS TÉCNICAS. 2006. NBR ISO 12466-2. Madeira Compensada - Qualidade de colagem Parte 2: Requisitos. PRATA JG. 2010. Estudo da viabilidade tecnológica do uso de espécies de Pinus tropicais para produção de painéis colados lateralmente (Edge Glued Panels - EGP). Tese (Doutorado em Engenharia Florestal). Curitiba: UFPR. $117 \mathrm{p}$.

SELBO ML. 1975. Adhesive bonding of wood. Technical bulletin. U.S. Department of Agriculture. V. 1512. Washington, D.C. $124 \mathrm{p}$.

SELLERS JR T. 1985. Plywood and adhesive technology.
New York: Marcel Dekker. 661 p.

SJÖSTRÖM E. 1981. Wood Chemistry - Fundamentals and Applications. New York. 223 p.

SBS - SOCIEDADE BRASILEIRA DE SILVICULTURA. 2008. Fatos e números do Brasil florestal. São Paulo: SBS. $92 \mathrm{f}$.

STAMM AJ. 1964. Wood and cellulose science. The Ronald Press Company. New York. 549 p.

TAPPI - TECHNICAL ASSOCIATION OF THE PULP AND PAPER INDUSTRY. 1994. TAPPI-207: Water solubility of wood. Atlanta.

TAPPI - TECHNICAL ASSOCIATION OF THE PULP AND PAPER INDUSTRY. 1994. TAPPI 211: Ash in wood, pulp, paper and paperboard: combustion at $525^{\circ} \mathrm{C}$. Atlanta. TAPPI - TECHNICAL ASSOCIATION OF THE PULP AND PAPER INDUSTRY. 1994. TAPPI 212: One percent sodium hydroxide solubility of wood and pulp. Atlanta. TAPPI - TECHNICAL ASSOCIATION OF THE PULP AND PAPER INDUSTRY. 2002. TAPPI 252. pH and electrical conductivity of hot water extracts of pulp, paper, and paperboard. Atlanta.

TSOUMIS G. 1991. Science and technology of wood: structure, properties and utilization. New York. 494 p. 